\title{
Grueneberg Ganglion Neurons Are Finely Tuned Cold Sensors
}

\author{
Andreas Schmid, ${ }^{1}$ Martina Pyrski, ${ }^{1}$ Martin Biel, ${ }^{2}$ Trese Leinders-Zufall, ${ }^{1}$ and Frank Zufall ${ }^{1}$ \\ ${ }^{1}$ Department of Physiology, University of Saarland School of Medicine, 66421 Homburg, Germany, and ${ }^{2}$ Munich Center for Integrated Protein Science and \\ Department of Pharmacy, Center for Drug Research, Ludwig-Maximilians Universität München, 81377 Munich, Germany
}

The Grueneberg ganglion is a newly appreciated nasal subsystem with neural connections to the olfactory forebrain, but its functional role has not been well defined. Here, we assess whether Grueneberg ganglion neurons (GGNs) function as thermosensors. By investigating the effect of acute temperature changes on the cytosolic $\mathrm{Ca}^{2+}$ concentration of genetically labeled mouse GGNs (either gender), we demonstrate that GGNs are thermosensory neurons specialized to detect a temperature decline within a given temperature window. Furthermore, GGNs comprise a relatively homogeneous cell population with respect to temperature sensitivity. GGNs do not respond to ligands of the temperature-sensitive TRP channels TRPM8 and TRPA1, suggesting a novel mechanism for temperature sensing. One possibility is a cGMP-mediated mechanism, as GGNs express the receptor guanylyl cyclase GC-G, the cGMP-sensitive phosphodiesterase PDE2 and the cGMP-sensitive channel CNGA3. Surprisingly, Cnga3-null mice show normal cooling-induced Ca ${ }^{2+}$ responses although cGMP-dependent $\mathrm{Ca}^{2+}$ increases are absent in these mice. Rather, the cooling-induced $\mathrm{Ca}^{2+}$ response of GGNs depends critically on the activity of a tetrodotoxin-sensitive voltage-gated sodium channel whereas the cGMP-dependent $\mathrm{Ca}^{2+}$ signal does not. These findings establish the Grueneberg ganglion as a sensory organ mediating cold-evoked neural responses, possibly in conjunction with the sensing of other stress- or fear-related chemical social cues.

\section{Introduction}

The Grueneberg ganglion, located at the rostral tip of the nose (Grüneberg, 1973), was rediscovered just a few years ago. It consists of a cluster of neurons- henceforward referred to as Grueneberg ganglion neurons (GGNs) - that express olfactory marker protein (OMP) and project their axons to a small number of glomeruli in the caudal main olfactory bulb (Fuss et al., 2005; Koos and Fraser, 2005; Fleischer et al., 2006; Roppolo et al., 2006; Storan and Key, 2006). Interestingly, these glomeruli are near the necklace glomeruli innervated by olfactory sensory neurons expressing the receptor guanylyl cyclase GC-D (Fülle et al., 1995; Juilfs et al., 1997; Leinders-Zufall et al., 2007; Walz et al., 2007; for review, see Munger et al., 2009), and both GC-D-expressing neurons and GGNs express elements of a cGMP second messenger pathway, including the cGMP-specific cyclic nucleotide-gated channel CNGA3 and the cGMP-stimulated phosphodiesterase PDE2 (Juilfs et al., 1997; Meyer et al., 2000; Leinders-Zufall et al., 2007; Fleischer et al., 2009; Liu et al., 2009). They differ, however, in the membrane-bound guanylyl cyclases they express; GGNs express guanylyl cyclase type G but not GC-D (Fleischer et al., 2009; Liu et al., 2009).

Received Feb. 4, 2010; revised April 14, 2010; accepted April 21, 2010.

This work was supported by Deutsche Forschungsgemeinschaft Grants Sonderforschungsbereich 530 (to F.Z.) and 391 (to M.B.). T.L.-Z. is a Lichtenberg Professor of the Volkswagen Foundation. We thank Peter Mombaerts and Katharina Zimmermann for providing OMP-GFP and TRPA1-deficient mice, respectively; Joerg Fleischer and Heinz Breer for sharing unpublished results; Jan Weiss for patch-clamp experiments; Barbara Niemeyer for advice; and Steven Munger for valuable comments.

Correspondence should be addressed to Frank Zufall, University of Saarland School of Medicine, Department of Physiology, Building 58, 66421 Homburg, Germany. E-mail: frank.zufall@uks.eu.

DOI:10.1523/JNEUROSCI.0608-10.2010

Copyright $\odot 2010$ the authors $\quad 0270-6474 / 10 / 307563-06 \$ 15.00 / 0$
An important step in elucidating the functional relevance of the Grueneberg ganglion is the identification of sensory stimuli that are detected by GGNs. Thus far, only two studies have addressed this problem. Mamasuew et al. (2008) used immediate early gene expression to suggest that the Grueneberg ganglion is activated by cool ambient temperature. By contrast, Brechbühl et al. (2008), using cellular $\mathrm{Ca}^{2+}$ imaging, found no evidence for temperature-induced responses in GGNs but were able to activate the cells with an as yet unidentified chemical that they collected during killing of mice with $\mathrm{CO}_{2}$. Here we focus on the temperature sensitivity of individual mouse GGNs by analyzing $\mathrm{Ca}^{2+}$ responses in live tissue slices. Our results demonstrate that these cells are capable of sensing an immediate temperature decline within a given temperature range and thus function as finely tuned cold detectors. Given that GGN axons seem to activate a common pathway involved in stress or fear responses (Brechbühl et al., 2008) and that mouse pups exhibit poorly developed thermoregulation during the first week of life and are likely to die if they remain out of the nest (Crawley, 2000), our findings suggest that GGNs could signal a social stress response due to cooling.

\section{Materials and Methods}

Animals. Experiments used three strains of mice: (1) OMP-GFP ${ }^{+/-}$ mice, heterozygous for both $O M P$ and GFP (green fluorescent protein) (Potter et al., 2001); (2) $\mathrm{Cnga3}^{-/-} \mathrm{OMP}-\mathrm{GFP}^{+/-}$mice in which genetically labeled GGNs were devoid of a functional CNGA3 channel [this strain was obtained by crossing $\mathrm{Cnga3}^{-/-}$mice (Biel et al., 1999; Leinders-Zufall et al., 2007) with OMP-GFP mice]; and (3) mice deficient for the transient receptor potential (TRP) channel TRPA1 $\left(\operatorname{Trpa1}^{-/-}\right.$) (Kwan et al., 2006). The relevant Institutional Animal Care and Use Committee approved all procedures. 

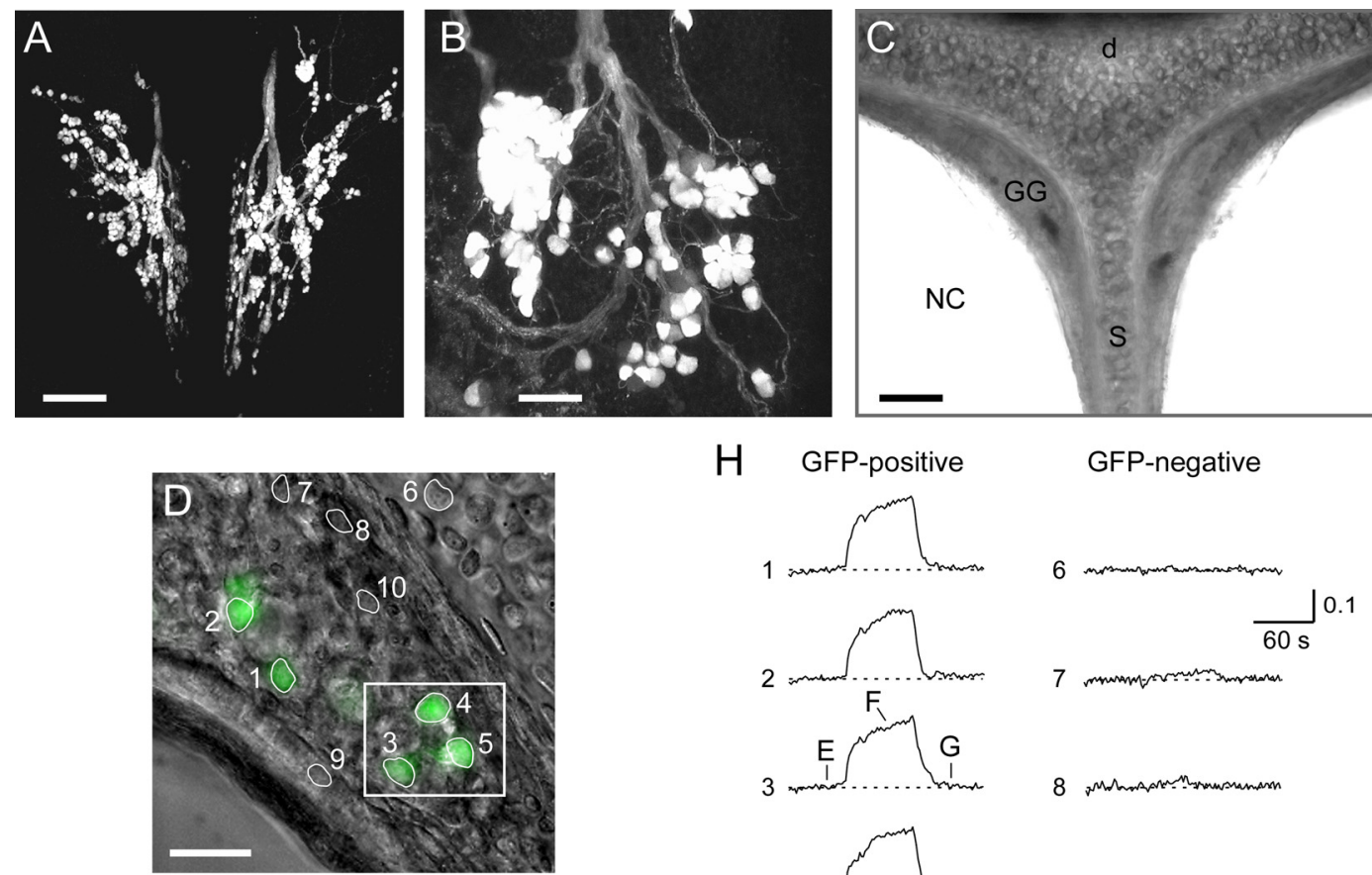

$\mathrm{H}$

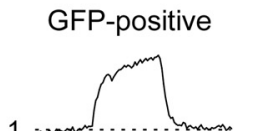

GFP-negative
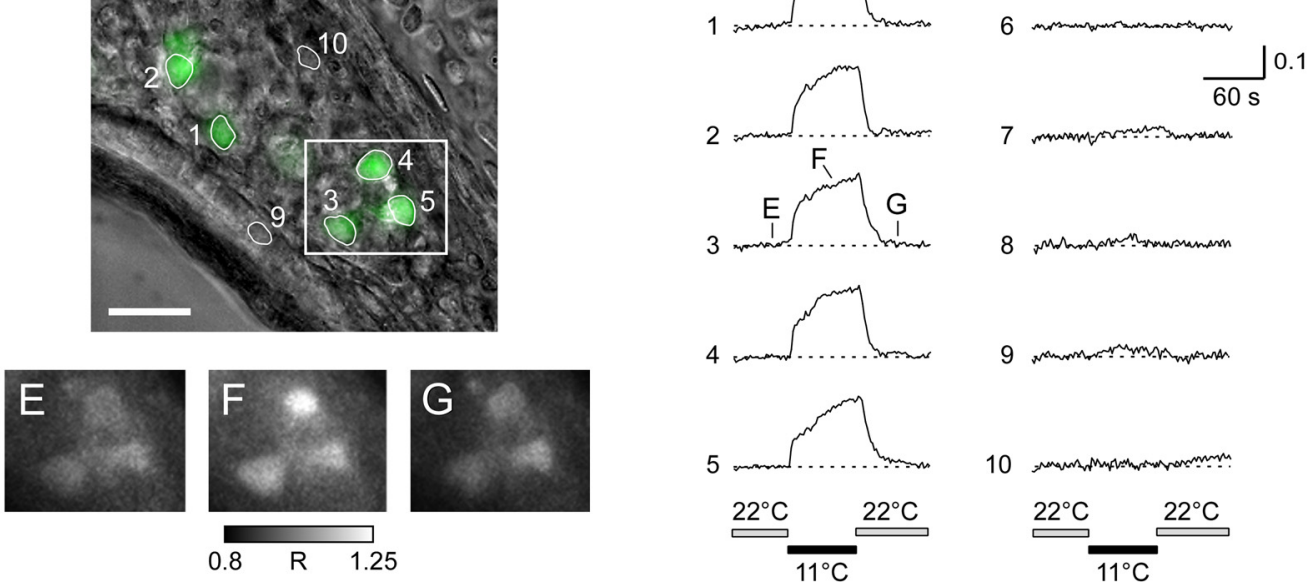

Figure 1. $\quad \boldsymbol{A}, \boldsymbol{B}$, Reconstructed low $(\boldsymbol{A})$ and higher $(\boldsymbol{B})$ resolution confocal images obtained in a live tissue slice showing GGN cell bodies, axons, and nerve bundles identified by GFP fluorescence. Scale bars, $200 \mu \mathrm{m}(\boldsymbol{A}), 50 \mu \mathrm{m}(\boldsymbol{B})$. C, Low-resolution transmitted light image showing a live coronal slice through the anterior nose. NC, Nasal cavity; $S$, septum, GG, Grueneberg ganglion; $d$, dorsal. Scale bar, $150 \mu \mathrm{m}$. $\boldsymbol{D}$, Higher resolution image of a Grueneberg ganglion slice. GFP fluorescence has been superimposed onto the transmitted light image. Individual cells analyzed in $\boldsymbol{H}$ have been encircled. Scale bar, $30 \mu \mathrm{m}$. $\mathbf{E}-\mathbf{G}$, The region delimited by the white box in $\boldsymbol{D}$ is magnified to show the temporal evolution of $\mathrm{Ca}^{2+}$ fluorescence (time series images) of cells $3-5$ following cooling from $22^{\circ} \mathrm{C}(\boldsymbol{E})$ to $11^{\circ} \mathrm{C}(\boldsymbol{F})$ and back to $22^{\circ} \mathrm{C}(\boldsymbol{G})$. The time points at which these images were acquired are indicated in the response of cell $3(\boldsymbol{H})$. $\boldsymbol{H}$, Ratiometric $\mathrm{Ca}^{2+}$ responses to cooling from $22^{\circ} \mathrm{C}$ to $11^{\circ} \mathrm{C}$ compared in GFP-positive (1-5) and -negative (6-10) cells.

Calcium imaging and data analysis. We used newborn mice [postnatal day 1 (P1)-P10] to prepare coronal tissue slices (60- to $100-\mu$ m-thick) of the Grueneberg ganglion. Isolated nasal vestibules were embedded in $4 \%$ low-gelling-temperature agarose prepared in saline consisting of (in mM): $140 \mathrm{NaCl}, 5 \mathrm{KCl}, 1 \mathrm{CaCl}_{2}, 1 \mathrm{MgCl}_{2}, 10$ HEPES, 300 mOsm, pH 7.3. Slices were cut on a vibratome (Microm HM $650 \mathrm{~V}$ ) and collected in ice-cold, oxygenated $\left(95 \% \mathrm{O}_{2} / 5 \% \mathrm{CO}_{2}\right.$ ) extracellular solution containing the following (in mM): $120 \mathrm{NaCl}, 25 \mathrm{NaHCO}_{3}, 5 \mathrm{KCl}, 1 \mathrm{MgSO}_{4}, 1$ $\mathrm{CaCl}_{2}, 10$ glucose, $5 \mathrm{BES}, \mathrm{pH}$ 7.3. Most experiments used one slice per mouse. The tissue was loaded with $15 \mu \mathrm{M}$ Fura-2/AM (Invitrogen) for $1 \mathrm{~h}$ at $22^{\circ} \mathrm{C}$ in oxygenated solution. We performed ratiometric $\mathrm{Ca}^{2+}$ imaging on an inverted microscope (Zeiss Axiovert 135) equipped with monochromator and cooled CCD camera system (Till Photonics). Fura-2 ratios were determined at 340 and $380 \mathrm{~nm}$ excitation wavelengths. Image pairs were acquired at $0.5 \mathrm{~Hz}$ and analyzed using Till Vision and Igor Pro software (Wavemetrics). The temperature of the perfusion buffer was controlled with a Peltier heater/cooler device (Warner Instruments). The actual temperature in the bath solution was continuously monitored with a miniature temperature sensor placed close to the preparation. Vomeronasal organ (VNO) slices were prepared as described previously (LeindersZufall et al., 2000). Chemicals were purchased from Sigma unless otherwise stated. Statistical analysis was performed with NCSS 2004 software. $p$ values $<0.02$ were considered statistically significant. Unless otherwise stated, results are presented as means \pm SD.

Immunohistochemistry. Following anesthesia, P6-P10 mice were transcardially perfused with PBS, followed by $4 \%(\mathrm{w} / \mathrm{v})$ paraformaldehyde in PBS. Tissue containing the Grueneberg ganglion was dissected, incubated overnight in $30 \%$ sucrose in PBS at $4^{\circ} \mathrm{C}$, embedded in O.C.T. (Tissue-Tek), and snap-frozen in a dry ice/2-methylbutane bath. Coronal cryosections (10 $\mu \mathrm{m})$ were thaw-mounted onto glass slides (Polysciences) and incubated for $1 \mathrm{~h}$ in blocking solution (4\% horse serum, $0.3 \%$ Triton X-100 in PBS), followed by incubation in primary antibody prepared in blocking solution. For CNGA3 labeling we used a rabbit primary antiserum at 1:1000 (Michalakis et al., 2006). Nav1.8 labeling used a rabbit polyclonal serum (Sigma, 1:100 dilution) directed against the peptide CEDEVAAKEGNSPGPQ. Secondary antibody was Alexa Fluor 555-conjugated donkey-anti-rabbit $\operatorname{IgG}(1: 1000$, Invitrogen). Confocal fluorescence images were acquired on a LSM 710/ConfoCor-3 microscope (Zeiss) and assembled and minimally adjusted in brightness using Adobe Photoshop 6.0.

\section{Results}

\section{GGNs comprise a cluster of thermosensory neurons}

To assess the function of individual GGNs, we developed a new coronal slice preparation and used ratiometric $\mathrm{Ca}^{2+}$ imaging that enabled the simultaneous, real-time recording of stimulusinduced responses from multiple, genetically labeled GGNs with intact cellular organization. Tissue slices were prepared from gene-targeted mice in which GGNs were visually identified on the basis of their GFP expression (OMP-GFP ${ }^{+/-}$mice) (Potter et al., 2001) (Fig. 1 $A-D$ ). Most experiments used tissue obtained from neonatal mice (P1-P10) (Fig. 1C); a few slices were prepared from weaned animals (see below).

We first sought to determine whether GGNs respond to thermostimuli. This was achieved by investigating the effect of acute 
A

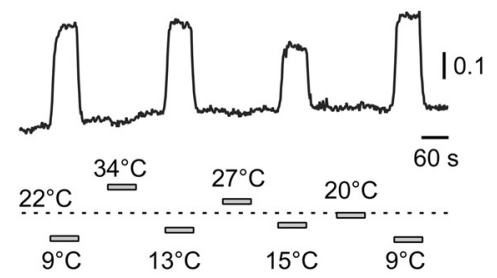

C

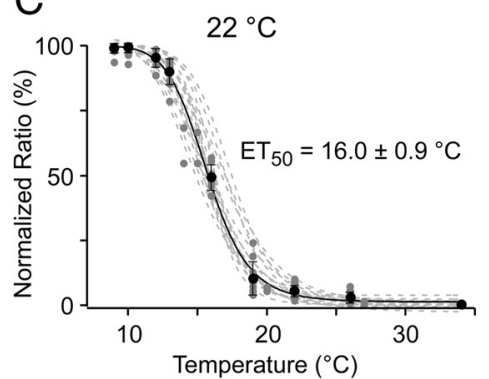

$\mathrm{E}$

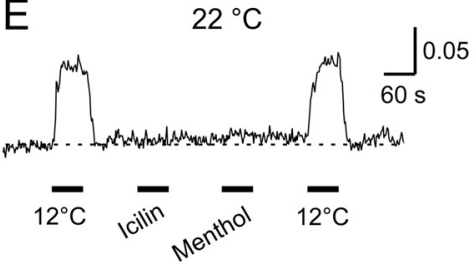

G

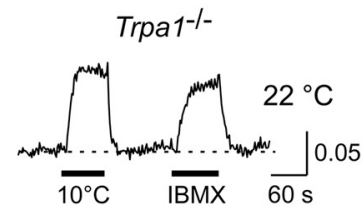

I

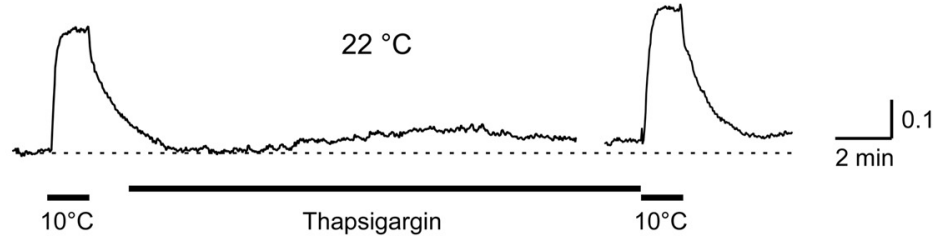

Figure 2. Dynamic range and properties of cold-evoked $\mathrm{Ca}^{2+}$ responses of $\mathrm{GGNs} . \boldsymbol{A}, \boldsymbol{B}$, Examples of $\mathrm{GGN} \mathrm{Ca}^{2+}$ signals in response to several temperature stimuli, starting from a basal temperature of $22^{\circ} \mathrm{C}(\boldsymbol{A})$ or $34^{\circ} \mathrm{C}(\boldsymbol{B})$, respectively. $\boldsymbol{C}, \boldsymbol{D}$, Plots of individual temperature-response curves of single GGNs (dashed lines) obtained under similar conditions as those shown in $\boldsymbol{A}$ and B. Solid lines represent average curves. $\boldsymbol{E}, \boldsymbol{F}, \mathrm{GGNs}$ fail to produce a $\mathrm{Ca}^{2+}$ rise in response to treatment with icilin $(500 \mu \mathrm{m}, \boldsymbol{E})$, menthol $(5 \mathrm{~mm}, \boldsymbol{E})$, or AITC $(100 \mu \mathrm{M}, \boldsymbol{F}) . \boldsymbol{G}, \boldsymbol{H}$, Normal $\mathrm{Ca}^{2+}$ responses to cooling $\left(10^{\circ} \mathrm{C}\right)$ and IBMX (100 $\left.\mu \mathrm{M}\right)$ in $\mathrm{GGNs}$ from $\operatorname{Trpa1}^{-1-}$ mice. Number of cells is indicated above each bar $(\boldsymbol{H}) ; p=0.67$, unpaired $t$ test; $n$.s., not significant. $\boldsymbol{I}$, Treatment with thapsigargin $(20 \mu \mathrm{m})$ to deplete intracellular $\mathrm{Ca}^{2+}$ stores does not eliminate $\mathrm{GGN}$ cold-evoked $\mathrm{Ca}^{2+}$ response.

temperature changes on the cytosolic $\mathrm{Ca}^{2+}$ concentration. A decline in temperature of the perfusion solution, from $22^{\circ} \mathrm{C}$ to $11^{\circ} \mathrm{C}$, caused a profound rise in intracellular $\mathrm{Ca}^{2+}$ in GFPpositive cells (Fig. $1 \mathrm{E}-\mathrm{H}$ ). This $\mathrm{Ca}^{2+}$ signal consisted of an initial rapid response followed by a slower more sustained rise [with a time to $30 \%$ of maximum of $3 \pm 1.73 \mathrm{~s}(n=5)$ ] (Fig. $1 H)$. Upon removal of the stimulus, the $\mathrm{Ca}^{2+}$ fluorescence decayed back to baseline, with a time constant of $5.7 \pm 1.7 \mathrm{~s}(n=5)$. Analysis of individual cells in the tissue slices showed that the vast majority of GFP-positive cells produced such $\mathrm{Ca}^{2+}$ responses (116/152 cells, $76 \% ; n=20$ slices), whereas no such $\mathrm{Ca}^{2+}$ responses were observed in GFP-negative cells located in the same slices (Fig. $1 D, H)$. GFP-positive sensory neurons of the $\mathrm{VNO}$, which also express OMP, did not produce a cooling-induced $\mathrm{Ca}^{2+}$ rise $(n=$
6 VNO slices), indicating that these $\mathrm{Ca}^{2+}$ signals are specific to OMP-positive GGNs. The responses were not caused by GFP expression itself, as cooling-induced $\mathrm{Ca}^{2+}$ responses were also observed in GGNs obtained from wild-type mice (data not shown). GFP fluorescence did not change as a result of cooling (supplemental Fig. 1, available at www.jneurosci.org as supplemental material). Cooling-induced $\mathrm{Ca}^{2+}$ responses in individual GGNs were not only recorded in neonates but also in weaned animals $(>\mathrm{P} 21, n=8$; data not shown). Thus, OMP-positive GGNs are thermosensory neurons with connections to the olfactory bulb.

\section{Cold-evoked $\mathrm{Ca}^{2+}$ responses are graded and time-locked}

Next, we determined the stimulusresponse relationship and dynamic range of individual GGNs for different temperature steps. Starting from a bath (basal) temperature of $22^{\circ} \mathrm{C}$, cold stimuli (to values ranging from $20^{\circ} \mathrm{C}$ to $9^{\circ} \mathrm{C}$ ) produced a distinct $\mathrm{Ca}^{2+}$ rise, with the relative change in cytosolic $\mathrm{Ca}^{2+}$ depending on the magnitude of the temperature decrease (Fig. $2 \mathrm{~A})$. Stimuli reflecting an increase in temperature (to $27^{\circ} \mathrm{C}$ or $34^{\circ} \mathrm{C}$ ) did not evoke a $\mathrm{Ca}^{2+}$ rise (Fig. $2 A$ ). We determined the maximum of the plateau response and analyzed stimulus-response curves from 17 individual GGNs in 5 different slices and found that their response properties and dynamic ranges were almost identical (Fig. 2C). On average, these curves revealed a response threshold $\left(\mathrm{ET}_{05}\right)$ of $21.9^{\circ} \mathrm{C}$, a half-maximal response $\left(\mathrm{ET}_{50}\right)$ of $16.0^{\circ} \mathrm{C}$, and saturation $\left(\mathrm{ET}_{95}\right)$ of $11.9^{\circ} \mathrm{C}$ (Fig. 2C). Thus, GGNs appear to be a relatively homogeneous cell population with respect to temperature sensitivity. We obtained very similar results when we kept the bath temperature at $34^{\circ} \mathrm{C}(n=12$ cells, 4 slices), which approximately reflects the in situ temperature in the nasal cavity (Fig. $2 B, D$ ). Together, these findings indicate that GGNs function as unidirectional thermosensors that detect an immediate temperature decline within a relatively narrow temperature window.

\section{Ligands for classical cold sensors fail to stimulate GGNs}

Several TRP channels including TRPM8 and TRPA1 are known to be temperature-responsive and can be activated by cooling (for review, see Jordt et al., 2003; Nilius and Voets, 2007; Venkatachalam and Montell, 2007). These channels respond to both physical and chemical stimulation. For instance, TRPM8 is sensitive to the cooling agents menthol and icilin whereas TRPA1 can be activated by the mustard oil component allyl isothiocyanate (AITC). To explore whether the activity of TRPM8 or TRPA1 could account for the cooling-induced $\mathrm{Ca}^{2+}$ responses of GGNs, we examined the effects of icilin (500 $\mu \mathrm{M}, n=7$ slices), menthol ( $1-5$ 
$\mathrm{mM}, n=6$ slices $)$, and AITC $(100 \mu \mathrm{M}, n=$ 5 slices) on $\mathrm{GGN} \mathrm{Ca}^{2+}$ levels. These compounds had no effect on the cytosolic $\mathrm{Ca}^{2+}$ concentration of GGNs (Fig. 2 E, F). We obtained the same result when we used $50 \mu \mathrm{M}$ menthol (supplemental Fig. $2 A$, available at www.jneurosci.org as supplemental material; $n=3$ ). As a positive control, we showed that AITC elicited oscillatory $\mathrm{Ca}^{2+}$ responses in some OMPnegative, yet unidentified cells located outside the Grueneberg ganglion (supplemental Fig. $2 B, C ; n=4)$. Finally, we used TRPA1-deficient mice (Kwan et al., 2006) to demonstrate that normal cold responses occur in GGNs from these mice (Fig. $2 G, H ; n=18$ cells; 8 slices; 3 mice). Hence, the cold sensors TRPM 8 and TRPA1 are unlikely to underlie GGN cold detection. Consistent with our findings, previous in situ hybridization experiments found that GGNs lack TRPM8 expression (Fleischer et al., 2009).

The cooling-induced $\mathrm{Ca}^{2+}$ signals were fully preserved when the tissue was pretreated for $>15$ min with the SERCA pump inhibitor thapsigargin $(20 \mu \mathrm{M}, n=$ 5 slices) to deplete intracellular $\mathrm{Ca}^{2+}$ stores. Thus, $\mathrm{Ca}^{2+}$ release from intracellular stores is not essential for GGN cold responses (Fig. 2I).

GGNs respond to cGMP with a Cnga3-dependent $\mathrm{Ca}^{2+}$ rise Work in Caenorhabditis elegans has identified alternative mechanisms for temperature sensing that depend, in part, on intracellular cGMP signaling (Kuhara et al., 2008; Ramot et al., 2008). Remarkably, mouse GGNs also express elements of a cGMP second messenger pathway, including the cGMP-specific CNGA3 channel and the cGMP-stimulated phosphodiesterase PDE2 (Fleischer et al., 2009; Liu et al., 2009). To elucidate whether cGMP signaling is necessary for cellular $\mathrm{Ca}^{2+}$ responses in GGNs, we first applied the highly membrane-permeant phosphodiesterase inhibitor 3-isobutyl-1-methylxanthine (IBMX, $100 \mu \mathrm{M})$ to block the breakdown of cyclic nucleotides produced by constitutive enzyme activity. This treatment produced a profound $\mathrm{Ca}^{2+}$ rise in the vast majority of GGNs (Fig. 3A; 106 of 143 cells, 74\%). $\mathrm{Ca}^{2+}$ responses to IBMX and cooling could be induced in the same cells (Fig. $3 B$ ). Dose-response measurements of the IBMX-induced effect revealed an $\mathrm{EC}_{50}$ value of $76.2 \pm 12.9$ $\mu \mathrm{M}(n=25$ cells, 6 slices; Fig. $3 C)$. By contrast, the adenylyl cyclase activator forskolin $(50 \mu \mathrm{M})$ did not produce a $\mathrm{Ca}^{2+}$ increase in GGNs ( $n=8$ slices; Fig. $3 A$ ), consistent with the absence of cAMP-sensitive CNG channels in these cells (Roppolo et al., 2006). GGNs displayed robust $\mathrm{Ca}^{2+}$ responses upon stimulation with 8-bromo-cGMP ( $n=6$ slices; Fig. $3 D$ ) or the PDE2-selective inhibitor erythro-9-[2-hydroxy-3-nonyl]-adenine (EHNA; $n=$ 5 slices; Fig. $3 E$ ), providing direct evidence that an increase in intracellular cGMP causes a $\mathrm{Ca}^{2+}$ elevation in these cells.

To determine whether cGMP-mediated $\mathrm{Ca}^{2+}$ signaling in GGNs depends on $\mathrm{Ca}^{2+}$ entry through the $\mathrm{Ca}^{2+}$-permeable CNGA3 channel, we used CNGA3-deficient $\left(\mathrm{Cnga3}^{-/-} \mathrm{OMP}-\right.$ $\mathrm{GFP}^{+/-}$) mice. Using an antibody specific to CNGA3 (Michalakis et al., 2006), we observed labeling in highly localized, whip-like sub- cellular domains extending from the somata of OMP-GFP $P^{+/-}$ GGNs (Fig. 4A). Such structures have been shown to represent primary cilia of GGNs (Brechbühl et al., 2008; Liu et al., 2009). Thus, our results provide evidence that CNGA3 resides in the GGN cilia, in accord with previous results (Liu et al., 2009). Importantly, no such immunoreactivity was observed in CNGA3deficient GGNs (Fig. $4 B$ ), thus validating the specificity of the antibody staining of Figure $4 \mathrm{~A}$. Hence, the $\mathrm{Cnga3}^{-1-} \mathrm{OMP}$ $\mathrm{GFP}^{+/-}$mice provide a valuable model to assess the role of CNGA3 in GGN signal transduction.

We next compared $\mathrm{Ca}^{2+}$ responses to stimulation with elevated $\mathrm{K}^{+}$, IBMX and 8-bromo-cGMP in OMP-GFP ${ }^{+/-}$and $\mathrm{Cnga3}^{-/-} \mathrm{OMP}-\mathrm{GFP}^{+/-}$GGNs (Fig. 4C-E). IBMX- and 8-bromo-cGMP-induced $\mathrm{Ca}^{2+}$ elevations were strongly reduced or absent in GGNs of CNGA3-deficient mice, although these neurons could still respond to high $\mathrm{K}^{+}$. Therefore, we conclude that CNGA3 is responsible for the cGMP-induced $\mathrm{Ca}^{2+}$ signal in these cells and that general excitability remains intact in CNGA3deficient GGNs.

\section{Distinct $\mathrm{Ca}^{2+}$ signaling mechanisms mediate responses to cooling and cGMP}

The preceding results establish cGMP signaling via the CNGA3 channel as a vital mechanism for $\mathrm{Ca}^{2+}$ entry into GGNs. Next, we examined whether this mechanism underlies GGN thermosensitivity. We found that cooling from $22^{\circ} \mathrm{C}$ to $12^{\circ} \mathrm{C}$ produced a $\mathrm{Ca}^{2+}$ response in GGNs of $\mathrm{Cnga3}^{-/-} \mathrm{OMP}-\mathrm{GFP}^{+/-}$mice that was nearly indistinguishable in terms of response magnitude and time course from the responses obtained in OMP-GFP ${ }^{+/-}$control mice (Fig. $4 D-F$ ). To determine whether the dynamic range of the cold responses had shifted as a result of the Cnga3 deletion, we analyzed stimulus-response curves using the same protocols as in Figure 2C. There was no significant difference in response 

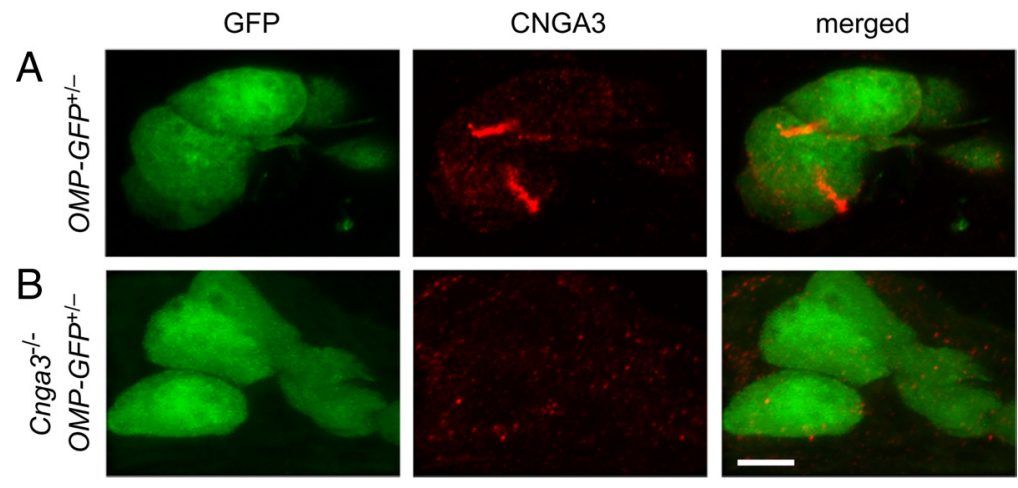

C

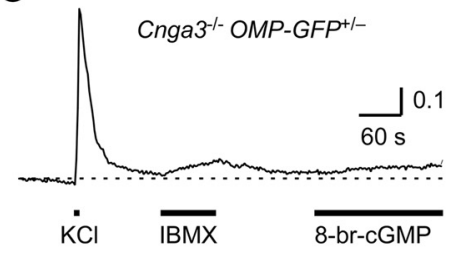

D

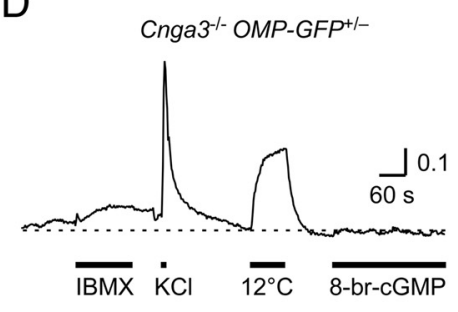

E
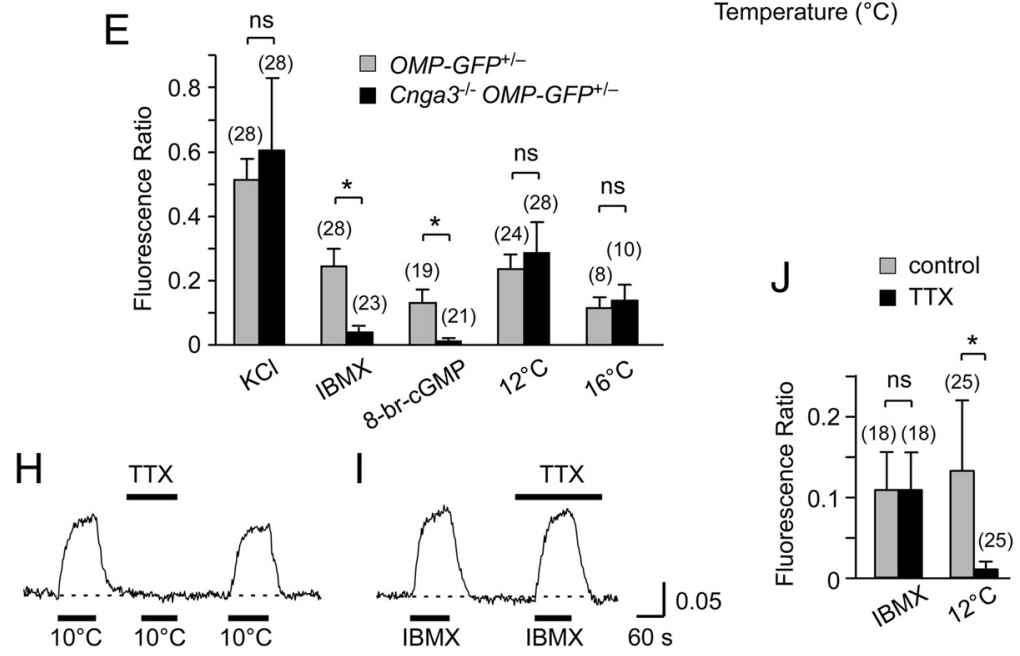

Figure 4. Differential $\mathrm{Ca}^{2+}$ signaling mechanisms underlie the effects of CGMP- and cold stimulation in GGNs. $A, B, C N G A 3$ immunoreactivity (red) is present in ciliary structures of GGNs in OMP-GFP ${ }^{+/-}$mice $(\boldsymbol{A})$ but absent in GGNs of $C$ nga $3^{-1-}$ OMP-GFP ${ }^{+/-}$mice $(\boldsymbol{B})$. Endogenous GFP expression (green) is observed in GGNs of both strains $(\boldsymbol{A}, \boldsymbol{B})$. Images shown are reconstructed Z-projections of $11(\boldsymbol{A})$ or $19(\boldsymbol{B})$ individual confocal sections, each $0.5 \mu \mathrm{m}$ thick. Scale bar, $5 \mu \mathrm{m}$. Results are representative of the analysis of 6 mice per strain. $C, D$, Examples of $\mathrm{Ca}^{2+}$ responses in $C$ nga $3^{-1-}$ OMP-GFP ${ }^{+1-}$ GGNs to stimulation with $60 \mathrm{~mm} \mathrm{~K}^{+}, 100 \mu \mathrm{M} \mathrm{IBMX}, 2 \mathrm{~mm}$ 8-bromo-CGMP, or cooling to $12^{\circ} \mathrm{C}$. $\boldsymbol{E}$, Comparison of stimulus-evoked $\mathrm{Ca}^{2+}$ peak responses in GGNs of OMP-GFP ${ }^{+/-}$and $C$ nga $3^{-1-}$ OMP-GFP ${ }^{+/-}$mice. Number of cells is indicated above each bar. ${ }^{*} p<0.0001$, unpaired $t$ test; $n$.s., not significant. $\boldsymbol{F}, \mathbf{G}, \mathrm{Ca}^{2+}$ responses to a range of temperature stimuli $(\boldsymbol{F})$ and analyzed stimulus-response curves $(\boldsymbol{G})$ in Cnga3 $^{-/-}$OMP-GFP ${ }^{+/-}$GGNs. $\boldsymbol{H}-\boldsymbol{J}$, Differential effect of tetrodotoxin $(1 \mu \mathrm{M})$ on $\mathrm{Ca}^{2+}$ responses to cooling or IBMX in OMP$\mathrm{GFP}^{+/-}$GGNs. Number of cells is indicated above each bar $(\boldsymbol{J}) .{ }^{*} p<0.0001$, paired $t$ test; n.s., not significant. Analysis of Cnga $^{-1-}$ OMP-GFP ${ }^{+/-}$GGNs gave the same results (data not shown). Basal temperature, $22^{\circ} \mathrm{C}$.

range or $\mathrm{ET}_{50}$ value between $\mathrm{OMP}-\mathrm{GFP}^{+/-}$and $\mathrm{Cnga3}^{-/-} \mathrm{OMP}$ $G F P^{+/-}$mice ( $p=0.06$, unpaired $t$ test), leading us to conclude that CNGA3 is not crucial for the primary transduction mechanism underlying cold detection in GGNs (Fig. 4F,G). Collec- tively, the results of Figure $4 A-G$ indicate that the CNGA3 channel is essential for IBMX- and 8-bromo-cGMP-dependent $\mathrm{Ca}^{2+}$ responses in GGNs but appears to be dispensable for cooling-induced $\mathrm{Ca}^{2+}$ signals of these cells.

Further support for differential mechanisms between cold- and cGMP-evoked $\mathrm{Ca}^{2+}$ signaling came from the analysis of the effect of the voltage-gated $\mathrm{Na}^{+}$(Nav) channel blocker tetrodotoxin (TTX, 1 $\mu \mathrm{M})$ on stimulus-induced $\mathrm{Ca}^{2+}$ signals in $\mathrm{OMP}-\mathrm{GFP}^{+/-}$GGNs (Fig. $4 \mathrm{H}-\mathrm{J}$ ). Whereas IBMX-induced $\mathrm{Ca}^{2+}$ rises were not affected by TTX treatment $(n=3$ slices), cold-induced responses were almost fully blocked by TTX ( $n=3$ slices), an effect that could be reversed (Fig. 4H-J). Thus, the cooling-induced $\mathrm{Ca}^{2+}$ response of GGNs depends critically on the activity of a TTX-sensitive Nav channel whereas the cGMP-dependent $\mathrm{Ca}^{2+}$ signal does not.

\section{Discussion}

By using $\mathrm{Ca}^{2+}$ imaging in genetically labeled GGNs, we showed that these cells are capable of detecting an immediate temperature decline and thus function as finely tuned cold sensors. GGNs produced a continuous, graded rise in intracellular $\mathrm{Ca}^{2+}$ upon cooling. Furthermore, response magnitude was correlated with the magnitude of the stimulus between $25^{\circ} \mathrm{C}$ to $10^{\circ} \mathrm{C}$. Responses were also time-locked to the stimulus. No clear dependence of the dynamic range of stimulus-response curves on basal temperature was observed, suggesting that GGNs are tuned to detect an absolute rather than a relative drop in temperature.

We found no evidence for an involvement of the classical cold sensors TRPM8 and TRPA1 in GGN cold sensing. Likewise, there was no evidence for a participation of the cGMP-specific CNGA3 channel in cooling-induced $\mathrm{Ca}^{2+}$ responses, although our results established cGMP signaling via CNGA3 as a vital mechanism for $\mathrm{Ca}^{2+}$ entry into GGNs. In contrast to cGMP-dependent $\mathrm{Ca}^{2+}$ responses, cooling-induced responses were eliminated by TTX treatment, indicating that they depend on a TTX-sensitive Nav channel. In primary neurons of the somatosensory system it is well established that a specific Nav channel (Nav1.8) enables noxious cold responsive afferents to respond to noxious cold temperatures (Zimmermann et al., 2007). GGNs, however, do not express Nav1.8 at detectable levels, ruling out an involvement of this channel in GGN cold responses (supplemental Fig. 3, available at www.jneurosci.org as supplemental material). As GGNs are ensheathed by glial cells and covered with keratinized epithelium 
(Brechbühl et al., 2008; Liu et al., 2009) it has proven impracticable to obtain patch-clamp recordings from these neurons to this point (J. Weiss and F.Z., unpublished observations).

As our findings provide direct evidence for a thermosensory role of GGNs they support and extend those of Mamasuew et al. (2008) using c-Fos expression. But how can they be reconciled with the results of Brechbühl et al. (2008)? The most intriguing explanation is that GGNs may act as multimodal sensors that are responsive to both thermo- and chemostimuli, thus joining an only recently discovered group of mammalian olfactory neurons with dual or multiple functions (Grosmaitre et al., 2007; Zufall and Munger, 2010). The newly characterized cGMP pathway is likely to underlie GGN chemoresponsivity, a conjecture that remains to be tested. In this model, GGNs could serve as a point of convergence between two seemingly disparate stimuli that both activate neuronal pathways involved in stress or fear responses. Separation from their nest and mother under low-temperature condition provides a life-threatening situation for rodent pups that induces profound social and physical stress, leading to the production of distinct ultrasonic vocalizations (Blumberg et al., 1992; Hashimoto et al., 2004; Szentgyörgyi et al., 2008). There is evidence that both ambient temperature and olfactory signals released by lactating rodent females are involved in such ultrasonic calls (Szentgyörgyi et al., 2008). The sensory capacity of the Grueneberg ganglion would be ideally suited to mediate this type of stress response.

\section{References}

Biel M, Seeliger M, Pfeifer A, Kohler K, Gerstner A, Ludwig A, Jaissle G, Fauser S, Zrenner E, Hofmann F (1999) Selective loss of cone function in mice lacking the cyclic nucleotide-gated channel CNG3. Proc Natl Acad Sci U S A 96:7553-7557.

Blumberg MS, Efimova IV, Alberts JR (1992) Ultrasonic vocalizations by rat pups: the primary importance of ambient temperature and the thermal significance of contact comfort. Dev Psychobiol 25:229-250.

Brechbühl J, Klaey M, Broillet MC (2008) Grueneberg ganglion cells mediate alarm pheromone detection in mice. Science 321:1092-1095.

Crawley JN (2000) What's wrong with my mouse? Behavioral phenotyping of transgenic and knockout mice. New York: Wiley.

Fleischer J, Hass N, Schwarzenbacher K, Besser S, Breer H (2006) A novel population of neuronal cells expressing the olfactory marker protein (OMP) in the anterior/dorsal region of the nasal cavity. Histochem Cell Biol 125:337-349.

Fleischer J, Mamasuew K, Breer H (2009) Expression of cGMP signaling elements in the Grueneberg ganglion. Histochem Cell Biol 131:75-88.

Fülle HJ, Vassar R, Foster DC, Yang RB, Axel R, Garbers DL (1995) A receptor guanylyl cyclase expressed specifically in olfactory sensory neurons. Proc Natl Acad Sci U S A 92:3571-3575.

Fuss SH, Omura M, Mombaerts P (2005) The Grueneberg ganglion of the mouse projects axons to glomeruli in the olfactory bulb. Eur J Neurosci 22:2649-2654.

Grosmaitre X, Santarelli LC, Tan J, Luo M, Ma M (2007) Dual functions of mammalian olfactory sensory neurons as odor detectors and mechanical sensors. Nat Neurosci 10:348-354.

Grüneberg H (1973) A ganglion probably belonging to the N. terminalis system in the nasal mucosa of the mouse. Z Anat Entwicklungsgesch 140:39-52.

Hashimoto H, Moritani N, Aoki-Komori S, Tanaka M, Saito TR (2004) Comparison of ultrasonic vocalizations emitted by rodent pups. Exp Anim 53:409-416.
Jordt SE, McKemy DD, Julius D (2003) Lessons from peppers and peppermint: the molecular logic of thermosensation. Curr Opin Neurobiol 13:487-492.

Juilfs DM, Fülle HJ, Zhao AZ, Houslay MD, Garbers DL, Beavo JA (1997) A subset of olfactory neurons that selectively express cGMP-stimulated phosphodiesterase (PDE2) and guanylyl cyclase-D define a unique olfactory signal transduction pathway. Proc Natl Acad Sci U S A 94:33883395.

Koos DS, Fraser SE (2005) The Grueneberg ganglion projects to the olfactory bulb. Neuroreport 16:1929-1932.

Kuhara A, Okumura M, Kimata T, Tanizawa Y, Takano R, Kimura KD, Inada H, Matsumoto K, Mori I (2008) Temperature sensing by an olfactory neuron in a circuit controlling behavior of C. elegans. Science 320:803-807.

Kwan KY, Allchorne AJ, Vollrath MA, Christensen AP, Zhang DS, Woolf CJ, Corey DP (2006) TRPA1 contributes to cold, mechanical, and chemical nociception but is not essential for hair-cell transduction. Neuron 50:277-289.

Leinders-Zufall T, Lane AP, Puche AC, Ma W, Novotny MV, Shipley MT, Zufall F (2000) Ultrasensitive pheromone detection by mammalian vomeronasal neurons. Nature 405:792-796.

Leinders-Zufall T, Cockerham RE, Michalakis S, Biel M, Garbers DL, Reed RR, Zufall F, Munger SD (2007) Contribution of the receptor guanylyl cyclase GC-D to chemosensory function in the olfactory epithelium. Proc Natl Acad Sci U S A 104:14507-14512.

Liu CY, Fraser SE, Koos DS (2009) Grueneberg ganglion olfactory subsystem employs a cGMP signaling pathway. J Comp Neurol 516:36-48.

Mamasuew K, Breer H, Fleischer J (2008) Grueneberg ganglion neurons respond to cool ambient temperatures. Eur J Neurosci 28:1775-1785.

Meyer MR, Angele A, Kremmer E, Kaupp UB, Muller F (2000) A cGMPsignaling pathway in a subset of olfactory sensory neurons. Proc Natl Acad Sci U S A 97:10595-10600.

Michalakis S, Reisert J, Geiger H, Wetzel C, Zong X, Bradley J, Spehr M, Hüttl S, Gerstner A, Pfeifer A, Hatt H, Yau KW, Biel M (2006) Loss of CNGB1 protein leads to olfactory dysfunction and subciliary cyclic nucleotidegated channel trapping. J Biol Chem 281:35156-35166.

Munger SD, Leinders-Zufall T, Zufall F (2009) Subsystem organization of the mammalian sense of smell. Annu Rev Physiol 71:115-140.

Nilius B, Voets T (2007) Neurophysiology: channelling cold reception. Nature 448:147-148.

Potter SM, Zheng C, Koos DS, Feinstein P, Fraser SE, Mombaerts P (2001) Structure and emergence of specific olfactory glomeruli in the mouse. J Neurosci 21:9713-9723.

Ramot D, MacInnis BL, Goodman MB (2008) Bidirectional temperaturesensing by a single thermosensory neuron in C. elegans. Nat Neurosci 11:908-915.

Roppolo D, Ribaud V, Jungo VP, Lüscher C, Rodriguez I (2006) Projection of the Grüneberg ganglion to the mouse olfactory bulb. Eur J Neurosci 23:2887-2894.

Storan MJ, Key B (2006) Septal organ of Grüneberg is part of the olfactory system. J Comp Neurol 494:834-844.

Szentgyörgyi H, Kapusta J, Marchlewska-Koj A (2008) Ultrasonic calls of bank vole pups isolated and exposed to cold or to nest odor. Physiol Behav 93:296-303.

Venkatachalam K, Montell C (2007) TRP channels. Annu Rev Biochem 76:387-417.

Walz A, Feinstein P, Khan M, Mombaerts P (2007) Axonal wiring of guanylate cyclase-D-expressing olfactory neurons is dependent on neuropilin 2 and semaphorin 3F. Development 134:4063-4072.

Zimmermann K, Leffler A, Babes A, Cendan CM, Carr RW, Kobayashi J, Nau C, Wood JN, Reeh PW (2007) Sensory neuron sodium channel Nav1.8 is essential for pain at low temperatures. Nature 447:855-858.

Zufall F, Munger SD (2010) Receptor guanylyl cyclases in mammalian olfactory function. Mol Cell Biochem 334:191-197. 